\title{
Pepsico promotion under the ASA cosh
}

Heidi Bernard

Journal of Direct, Data and Digital Marketing Practice (2013) 14, 269-271. doi:10.1057/dddmp.2013.10

Topic: Promotional marketing

Who: Advertising Standards Authority (ASA); PepsiCo International

Ltd (PepsiCo)

When: 21 November 2012

Where: London

Law stated as at: 4 December 2012

\section{What happened?}

\section{The complaint}

\section{The response}

\section{Monitoring for robot entries}

Pepsi's prize promotion offered the chance to win $£ 500$ every hour. The text stated: 'For a chance to win, enter the last 4 digits of your barcode at http://www.pepsi.co.uk or text 62948'.

One complainant found that the entry codes were not unique and had been posted online by consumers. This allowed them to be used by those who had not purchased the product or followed the no-purchase entry process.

The second complainant who won several times and was informed that only one win would be honoured objected that the restriction was not made clear.

PepsiCo pointed out that the product label stated that no purchase was necessary. Consumers could enter the promotion either by purchasing the product or entering online with no purchase required.

PepsiCo added that the cost of having unique codes on each label was high, and instead they monitored contact details of entrants to ensure that they did not enter more than once an hour. They said that consumers were finding ways of entering promotions without having to purchase the product and would share details of how to do this online. To ensure that the promotion was administered fairly and honourably, PepsiCo restricted the number of times consumers could enter and monitored their contact details.

On the second complaint, PepsiCo said that the terms and conditions made clear the restriction on the number of entries: 'There is a limit of one entry per mobile phone number/email address per hourly prize draw. Only one code can be entered at a time. No bulk, consumer group, third party or agent entries will be valid'.

PepsiCo monitored entries manually to ensure that mass submissions were not being received from single IP addresses. In addition, entrants had to input a 'capture code' before submitting their entry, which prevented users from being able to build robots in order to enter multiple times. Furthermore, time limitations were added, and therefore there was a maximum of two entries every 60 seconds.

PepsiCo said that in 6 weeks one entrant and his family entered over 11,000 times using a high number of slightly varied email addresses. 
The ASA's assessment

\section{Unfair promotional practice}

Some draws were entered more than 500 times within the hour. Members of the family's entries had been selected as winners on multiple occasions.

There was a delay between these wins being confirmed and PepsiCo identifying them as having been automatically generated. PepsiCo did not know the exact mechanism that had been used, but said it was difficult to see how an individual could complete the form manually so many times. The entries were considered to be bulk, and bulk entries were not valid under the promotion terms and conditions.

Accordingly, PepsiCo said that it was justified to withhold prizes if participants had not met the qualifying criteria set out in the terms and conditions. As soon as they became aware of problematic entries, PepsiCo informed the entrants involved that the prizes would be withheld, aside from the initial win for each participant in the family. Although they had been informed that they had won on multiple occasions, it would be unfair to other entrants to award prizes that were won via bulk entries and a response was provided in relation to the other draws within 28 days of the draw taking place. The draws that had been won by bulk or automated entries had been redrawn, and therefore they had dealt with the matter fairly and honourably.

PepsiCo had not breached CAP Code (Edition 12) Rule 8.2 (Sales promotions) in relation to the first complaint.

The ASA noted that entrants who obtained entry codes online did not have to purchase the product or follow the relevant no-purchase entry process, which the terms and conditions stated was by post. The ASA considered it reasonable for advertisers not to use unique codes, provided promotions were administered fairly.

With regard to the second complaint, the ASA held that PepsiCo had breached CAP Code (Edition 12) Rules 8.2 and 8.17 (Sales promotions) and 8.23, 8.27 and 8.28.1 (Prize promotions). Although generating multiple e-mail addresses to make a large number of entries was not within the spirit of the promotion, the terms and conditions did not explicitly forbid this practice.

The terms and conditions did prohibit 'bulk' entries and this would be likely to be interpreted as suggesting that entries generated automatically and, in particular, not by individuals would not be accepted. However, PepsiCo had not provided evidence to show that the complainant's entries were made by the automatic generation of entries as opposed to manually creating numerous, slightly different email addresses. Therefore, the prohibition of bulk entries did not apply in this case.

Furthermore, the terms and conditions did not clearly prohibit making multiple entries from a single IP address, which had happened in this case.

The complainant and his family members received confirmation of several wins, and to withdraw the prizes subsequently — in some cases over a month after the notification of the wins - caused unnecessary disappointment as they had used different e-mail addresses for each entry.

The terms and conditions of the promotion did not make the position sufficiently clear in relation to the practice that had caused the problem 


\section{Why this matters}

in this case, and because of the unnecessary disappointment caused the promotion had not been administered fairly. PepsiCo were told to ensure that promotions were administered fairly and significant conditions of promotions were made clear in the future.

The decision seems harsh, given that few would consider the entry method used by the complainants to be within the spirit of the promotion.

However, other restrictions could have been included in the terms and conditions, such as one entry per person per hour (therefore preventing the same entrant using multiple e-mail addresses) and one entry per IP address per hour (preventing multiple entries per household). It was the absence of these that got PepsiCo in difficulty.

The case underlines the need to take meticulous care in drafting terms and conditions for multiple digital entry promotions in order to keep one step ahead of ever more ingenious promotion entrants.

Heidi Bernard, Paralegal, Osborne Clarke E-mail: Heidi.bernard@osborneclarke.com 